\title{
Systemic Antifungal Prophylaxis in Patients Hospitalized in Hematology Units in France: The AFHEM Cross-Sectional Observational Study
}

\author{
Jean-Pierre Gangneux · Jean El Cheikh • Raoul Herbrecht • \\ Ibrahim Yakoub-Agha · Jean-Baptiste Quiniou • Denis Caillot • \\ Mauricette Michallet
}

Received: October 19, 2017 / Published online: June 9, 2018

(C) The Author(s) 2018

\section{ABSTRACT}

Introduction: The frequency of invasive fungal diseases (IFDs) has increased in recent years. Within a context where both treatments and guidelines are fast evolving, we aim to shed new light on IFD management in hematologic departments in France.

Methods: A multicenter cross-sectional observational study was prospectively conducted in 24 French centers in September and October 2013.

Results: Four hundred ninety-four hospitalized children and adult patients suffering from hematologic malignancy were enrolled: 147

Enhanced digital features To view enhanced digital features for this article go to https://doi.org/10.6084/ m9.figshare.6383111.

J.-P. Gangneux ( $₫)$

Department of Parasitology and Myology, Hospital

Pontchaillou, Rennes, France

e-mail: Jean-Pierre.Gangneux@univ-rennes1.fr

J. El Cheikh

Department of Transplantation and Cellular

Therapy, Paoli Calmettes Institute, Marseille, France

R. Herbrecht

Department of Oncology and Hematology,

Strasbourg, France

I. Yakoub-Agha

LIRIC INSERM U995, Affiliated University Hospital,

Lille 2 University, Lille, France
(30\%) were allogeneic hematopoietic stem cell transplant (HSCT) recipients, 131 (27\%) were patients with acute myeloblastic leukemia or myelodysplastic syndrome (MDS), 71 (14\%) were patients with acute lymphoblastic leukemia who did not undergo allogeneic HSCT, and the 145 (29\%) remaining patients did not belong to the three above groups. Two hundred forty-six patients $(50 \%)$ received antifungal treatment, which was prophylactic in 187 (76\%) treated patients. These rates were similar across all groups (63-80\%). Patients received prophylaxis with an azole (79\%), intravenous amphotericin B formulation (10\%), echinocandin (9\%), or two combination drugs $(2 \%)$.

Conclusion: Results indicate that prophylaxis is the leading antifungal strategy in French hematology units, regardless of the disease condition, representing $76 \%$ of prescriptions for antifungal therapy.

\section{J.-B. Quiniou}

Department of Medical Affairs, Astellas Pharma

France, Levallois-Perret, France

\section{Caillot}

Department of Clinical Hematology, Affiliated

University Hospital, Dijon, France

M. Michallet

Department of Clinical Hematology, Hospital Lyon-

Sud, Pierre-Bénite, France 
Funding: Astellas Pharma France.Keywords: Antifungal prophylaxis; Hematology; Invasive fungal disease; Systemic antifungal treatment

\section{INTRODUCTION}

The frequency of invasive fungal diseases (IFD) has increased dramatically within the last few years mainly because of the growing number of immunocompromised patients [1]. Candida sp. and Aspergillus sp. are the main pathogenic fungal agents that may lead to severe infectious complications particularly in neutropenic patients, recipients of allogeneic hematopoietic stem cells transplants (HSCT), or solid organ transplants, as well as patients in intensive care units presenting with multiple risk factors (e.g., broad-spectrum antibiotics, intravascular catheters, kidney failure, dialysis, long-term intubation) [2, 3]. In addition, the mortality rate associated with IFD remains very high ( $\geq 40 \%$ ) [4].

IFDs are difficult to diagnose and treat although various clinical guidelines have been published in the US by the Infectious Diseases Society of America [5], in Europe by the European Conference on Infections in Leukaemia (ECIL) [6] and the European Society of Clinical Microbiology and Infectious Diseases [7], and in various countries [8-12] to help physicians in their practices.

Antifungal drugs are used according to four different approaches: (1) prophylaxis for patients with a high risk of developing an IFD but without apparent symptoms [13-16]; (2) empiric treatment for patients with suspected fungal infection in the absence of radiologic, microbiologic, histologic, or serologic evidence, which is a widely used strategy for neutropenic patients with persistent fever after 4-7 days under broad-spectrum antibiotics or who become febrile after a period of apyrexia $[17,18]$; (3) preemptive (also called diagnosticdriven) treatment where there is a high suspicion of IFD in high-risk patients with some radioclinical or biomarker evidence [19], including possible IFD, according to the
European Organization for Research and Treatment of Cancer/Invasive Fungal Infections Cooperative Group and the National Institute of Allergy and Infectious Diseases Mycoses Study Group (EORTC/MSG) criteria [20]; or (4) curative treatment for probable or proven IFD according to the EORTC/MSG criteria [20].

Within a context where both treatments and guidelines are fast evolving, this cross-sectional observational study aims to shed new light on IFD management in pediatric and adult hematologic units in France, describing the frequency of systemic antifungal prophylaxis, the characteristics of patients receiving antifungal prophylaxis, and the prescription practices used in clinical practice.

\section{METHODS}

\section{Study Design and Patients}

This was an observational, cross-sectional study carried out over 5 consecutive days in 2013. Although major changes in practices occurred when the empirical strategy emerged in the 2000s and then anti-filamentous chemoprophylaxis in 2007, we consider that practices changed only slightly between 2013 and 2018 and therefore this does not invalidate our observations. French hematologic units located in university hospital and medical cancer centers were invited to participate. All patients (children or adults) with hematologic malignancy hospitalized in participating hematologic units during the 5-day observational period and who gave their written informed consent were included in the study. No other selection criterion was applied. Each center participated in the study over 5 consecutive days, but due to organizational considerations, centers did not all participate in the study within the same period, and patient recruitment was spread over a period of 6 weeks.

\section{Data Source}

Data were entered by investigators or their staff on electronic case report forms (eCRFs), 
including antifungal strategies at inclusion, hospitalization conditions, IFD history, hematologic malignancy and underlying conditions, antifungal treatments and other ongoing treatments, and IFD classification established by the physician. Clinical signs, imaging, and other examinations related to IFD episodes were collected for the patients who received preemptive or curative treatment. All data were recorded through a secure online case report form.

\section{Compliance with Ethics Guidelines}

The data were anonymized before any analysis occurred. All procedures followed were in accordance with the ethical standards of the responsible committee on human experimentation (institutional and national) and with the Helsinki Declaration of 1964, as revised in 2013. Informed consent was obtained from all patients for being included in the study. According to French regulatory requirements, approvals from the French review boards (Comité Consultatif sur le Traitement de l'Information en matière de Recherche dans le domaine de la Santé and Commission Nationale de l'Informatique et des Libertés) were obtained.

\section{Statistical Analyses}

The statistical analyses performed were mainly descriptive. The variables were analyzed according to the following general rules: quantitative variables were described by the number of available and missing data, mean, standard deviation, first quartile, median, third quartile, and minimum and maximum; qualitative and ordinal variables were described by the number of available and missing data, frequency, and percentage (of the total number of values available) of each modality. Confidence intervals (CIs) at 95\% were calculated according to Wilson's method (with continuity correction). Subgroup analyses were performed according to the last systemic antifungal therapeutic strategy reported for patients treated at least 1 day during the 5 observation days. Antifungal prophylaxis was also described as primary (i.e., in the absence of a history of IFD) or secondary prophylaxis (in patients with a history of an IFD). A logistic regression model was used to determine the factors impacting the treatment with antifungal drugs. Multivariate analysis was preceded by univariate analysis; significant factor at the threshold of the univariate analysis was then introduced. It was based on conventional univariate statistical tests: distributions of qualitative variables were compared using the $\chi^{2}$ test or Fisher's exact test if the expected frequency in any of the cells of the contingency table was less than five. A stepwise selection method (forward and backward combination of methods) was used to automatically select the most appropriate factors to take the model factors into account.

All analyses were carried out using SAS 9.2 (SAS Institute Inc., Cary, NC, USA).

\section{RESULTS}

\section{Participating Centers}

Of the 31 French hematologic centers that initially agreed to participate in the study, 24 contributed patients. These active units had a total of 717 beds including 368 rooms with air treatment.

Twenty-two units were in university hospitals, and the two others were in medical cancer centers. Sixteen units were adult, and eight were pediatric. Two units were exclusively adult HSCT units.

\section{Patients}

Four hundred ninety-four patients were enrolled in the study between 16 September 2013 and 25 October 2013.

Most patients (87\%) were adults, 288 (58\%) suffered from acute leukemia, and $41(8 \%)$ and 147 (30\%) were recipients of autologous or allogeneic HSCT, respectively. Among those who received an allogeneic HSCT, 123 (84\%) had recently been allo-transplanted (for less than 6 months). Thirty-seven percent of the patients were in relapse or refractory phase, and $231(47 \%)$ were in partial or complete remission. Neutropenia was present for at least 
10 days in 127 patients (26\%), and 50 patients $(10 \%)$ had a persistent fever refractory to antibiotic therapy. Three hundred forty-six patients (70\%) had been hospitalized in the unit for less than 15 days. A total of 313 patients (63\%) entered a room with air treatment, most of them $(89 \%)$ since their first day of entry in the unit: 172 patients (55\%) were placed in a laminar air flow room or Immunair ${ }^{\mathrm{TM}}$ bed, 88 patients (28\%) in a highly purified HEPA-filtered room, and $53(17 \%)$ in a conventional room with Plasmair ${ }^{\mathrm{TM}}$ or the equivalent. Thirteen percent of the patients had already experienced an IFD episode.

These 494 patients were classified into four groups: group 1 included the allogeneic HSCT recipients $(n=147)$, group 2 included patients suffering from acute myeloblastic leukemia (AML) or myelodysplastic syndrome (MDS) $(n=131)$, group 3 included patients suffering from acute lymphoblastic leukemia (ALL) $(n=71)$, and group 4 included all patients not included in groups 1,2 , or $3(n=145)$. Their characteristics are summarized in Table 1.

The demographic characteristics of the patients belonging to groups 1,2 , and 4 were similar. Because the patients from group 3 presented with ALL, this group included more children than the other groups (48\%), and the median age of adult patients was lower (39.8 years in group 3 versus 51.0, 58.0, and 64.6 years in groups 1,2 , and 4, respectively). Regarding ongoing treatments, patients from group 1 were more likely to be treated with antibiotics (85\%), antiviral agents (88\%), and immunosuppressive treatments (69\%). Moreover, they were more often placed in a sterile room, a laminar air flow room, Immunair ${ }^{\mathrm{TM}}$ bed, or highly purified HEPA-filtered room (82\% vs. 60,41 , and $22 \%$ for groups 2,3 , and 4 , respectively).

Regarding the 64 (13\%) pediatric patients enrolled in the study, they had mean age of 8.4 years and were mainly suffering from ALL [32 patients (50\%)] or AML [20 patients (31\%)]. Less than $20 \%$ (12 patients) were HSCT recipients. Nineteen percent of the patients were in the relapse or refractory phase, and 38 (59\%) were in partial or complete remission. Neutropenia was present for at least 10 days in 17 patients $(27 \%)$, and 6 patients $(9 \%)$ had a persistent fever refractory to antibiotic therapy. Their characteristics are summarized in Table 2.

\section{Antifungal Strategies}

The frequency of antifungal treatment was 50\% (95\% CI 45.3-54.3), i.e., 246 patients received a systemic antifungal treatment (as a prophylactic, empiric, preemptive, or curative strategy) during at least 1 of the 5-day observational periods.

The frequency of antifungal strategies is presented in Table 3 for each of the four groups. One hundred eighty-seven (38\%) patients received antifungal prophylaxis, representing $76 \%$ of treated patients. The proportions of patients who received antifungal prophylaxis among those treated with antifungal agents were similar in the four groups: $80 \%$ in group 1 , $72 \%$ in group $2,63 \%$ in group 3 , and $80 \%$ in group 4. Primary antifungal prophylaxis was delivered to 145 patients ( $78 \%$ of the patients who received antifungal prophylaxis), and the remaining 42 patients received secondary antifungal prophylaxis. The frequency of secondary prophylaxis was higher in group 4 than in the other groups.

The frequency of antifungal strategies according to age group (i.e., adults and pediatrics) is presented in Table 2 . Of the 64 pediatric patients included in the study, 20 (31\%) were treated with systemic antifungals; 13 received antifungal prophylaxis (mainly primary prophylaxis; 10 patients), representing $65 \%$ of treated patients.

\section{Characteristics of Patients Receiving Antifungal Prophylaxis}

Characteristics of the 187 patients who received antifungal prophylaxis are summarized in Table 4. Half of the patients from groups 2 and 3 (patients with AML, ALL, or MDS) presented with neutropenia for at least 10 days when enrolled in the study compared with $17 \%$ for groups 1 and 4 . Of the 95 patients treated with antifungal prophylaxis who had received allogeneic HSCT, $40 \%$ were in a neutropenic phase, 
Table 1 Characteristics of patients according to the pathology profile

\begin{tabular}{|c|c|c|c|c|c|}
\hline & $\begin{array}{l}\text { Group } 1 \\
n=147\end{array}$ & $\begin{array}{l}\text { Group } 2 \\
n=131\end{array}$ & $\begin{array}{l}\text { Group } 3 \\
n=71\end{array}$ & $\begin{array}{l}\text { Group } 4 \\
n=145\end{array}$ & $\begin{array}{l}\text { Total } \\
n=494\end{array}$ \\
\hline Gender (male) & $79(54)$ & $83(63)$ & $36(51)$ & $89(61)$ & $287(58)$ \\
\hline Adults & $1[35(92)]$ & $117(89)$ & $44(62)$ & $134(92)$ & $430(87)$ \\
\hline \multicolumn{6}{|l|}{ Age, years, median } \\
\hline Adult (range) & $\begin{array}{l}51.0 \\
\quad(21-71)\end{array}$ & $58.0(23-86)$ & $39.8(18-70)$ & $64.6(24-90)$ & $56.8(18-90)$ \\
\hline Children (range) & $6.3(0-12)$ & $8.9(1-17)$ & $10.5(1-17)$ & $8.8(0-16)$ & $8.4(0-17)$ \\
\hline \multicolumn{6}{|l|}{ Hematologic malignancy } \\
\hline Acute myeloid leukemia & $67(46)$ & $125(95)$ & & & $192(39)$ \\
\hline Myelodysplastic syndrome & $8(5)$ & $6(5)$ & & & $14(3)$ \\
\hline Acute lymphoblastic leukemia & $25(17)$ & & $71(100)$ & & $96(19)$ \\
\hline Hodgkin lymphoma & $13(9)$ & & & $13(9)$ & $26(5)$ \\
\hline Non-Hodgkin lymphoma & $11(7)$ & & & $83(57)$ & $94(19)$ \\
\hline Chronic lymphoid leukemia & $1(1)$ & & & $11(8)$ & $12(2)$ \\
\hline Myeloma & $9(6)$ & & & $32(22)$ & $41(8)$ \\
\hline Chronic myeloid leukemia & $6(4)$ & & & & $6(1)$ \\
\hline Other & $7(5)$ & & & $6(4)$ & $13(3)$ \\
\hline Disease status (relapse or refractory) & $92(64)$ & $17(13)$ & $12(17)$ & $60(41)$ & $181(37)$ \\
\hline \multicolumn{6}{|l|}{ Underlying conditions } \\
\hline Autologous transplant & 0 & $1(1)$ & $2(3)$ & $38(26)$ & $41(8)$ \\
\hline Allogeneic transplant ${ }^{a}$ & $147(100)$ & & & & $147(30)$ \\
\hline $\mathrm{GVHD}^{\mathrm{b}, \mathrm{c}}$ & $47(32)$ & & & & $47(32)$ \\
\hline Grade I-II acute GVHD & 23 & & & & 23 \\
\hline Grade III-IV acute GVHD & 18 & & & & 18 \\
\hline Chronic GVHD & 13 & & & & 13 \\
\hline Neutropenic phase ${ }^{c}$ & $64(44)$ & & & & $64(44)$ \\
\hline ANC $<0.5,10 / 1$ for at least 10 days & $35(24)$ & $62(47)$ & $20(28)$ & $10(7)$ & $127(26)$ \\
\hline $\begin{array}{l}\text { Persistent fever refractory to antibiotic } \\
\text { therapy }\end{array}$ & $15(10)$ & $20(15)$ & $5(7)$ & $10(7)$ & $50(10)$ \\
\hline Previous IFD & $33(22)$ & $17(13)$ & $9(13)$ & $3(2)$ & $62(13)$ \\
\hline \multicolumn{6}{|l|}{ Ongoing treatments } \\
\hline Chemotherapy & $63(43)$ & $106(81)$ & $60(85)$ & $98(68)$ & $327(66)$ \\
\hline Antibiotics & $125(85)$ & $104(79)$ & $48(68)$ & $92(63)$ & $369(75)$ \\
\hline
\end{tabular}


Table 1 continued

\begin{tabular}{|c|c|c|c|c|c|}
\hline & $\begin{array}{l}\text { Group } 1 \\
n=147\end{array}$ & $\begin{array}{l}\text { Group } 2 \\
n=131\end{array}$ & $\begin{array}{l}\text { Group } 3 \\
n=71\end{array}$ & $\begin{array}{l}\text { Group } 4 \\
n=145\end{array}$ & $\begin{array}{l}\text { Total } \\
n=494\end{array}$ \\
\hline Immunosuppressors & $102(69)$ & $10(8)$ & $22(31)$ & $27(19)$ & $161(33)$ \\
\hline Antivirals & $130(88)$ & $73(56)$ & $33(47)$ & $79(54)$ & $315(64)$ \\
\hline \multicolumn{6}{|l|}{ Time since entry in the unit } \\
\hline$\geq 30$ days & $37(25)$ & $19(15)$ & $8(11)$ & $7(5)$ & $71(14)$ \\
\hline Between 15 and 29 days & $25(17)$ & $32(24)$ & $11(15)$ & $9(6)$ & $77(16)$ \\
\hline$<15$ days & $85(58)$ & $80(61)$ & $52(73)$ & $129(89)$ & $346(70)$ \\
\hline Hospitalization in room with air treatment & $127(86)$ & $99(76)$ & $39(55)$ & $48(33)$ & $313(63)$ \\
\hline Laminar air flow room or Immunair ${ }^{\mathrm{TM}}$ bed $^{\mathrm{d}}$ & $96(76)$ & $48(49)$ & $18(46)$ & $10(21)$ & $172(55)$ \\
\hline Highly purified HEPA-filtered room ${ }^{\mathrm{d}}$ & $24(19)$ & $31(31)$ & $11(28)$ & $22(46)$ & $88(28)$ \\
\hline $\begin{array}{l}\text { Conventional room with plasmair }{ }^{\mathrm{TM}} \text { or } \\
\text { equivalent }^{\mathrm{d}}\end{array}$ & $7(5)$ & $20(20)$ & $10(26)$ & $16(33)$ & $53(17)$ \\
\hline
\end{tabular}

Data are $n(\%)$, unless otherwise specified

$A N C$ absolute neutrophil count, GVHD graft-versus-host disease, IFD invasive fungal disease

a 123 patients transplanted for less than 6 months

b Chronic and/or acute GVHD

c Percentage among recipients of allogeneic hematopoietic stem cell transplant

d Percentage among patients hospitalized in a room with air treatment

$10 \%$ had developed acute grade I-II graft-versushost disease (GVHD), 15\% had acute grade III-IV GVHD, and 7\% presented with chronic GVHD. One hundred fifty-seven patients were placed in a room with air treatment, with a similar proportion in each of the four groups. However, of the $88 \%$ of patients in a room with sterile air treatment (in the laminar air flow room, Immunair ${ }^{\mathrm{TM}}$ bed, or highly purified HEPA-filtered room), there were proportionately more patients from group 1 than in the other groups. Nineteen patients who received antifungal prophylaxis did not enter a sterile room, but were only placed in a conventional room with Plasmair ${ }^{\mathrm{TM}}$ or the equivalent.

Factors associated with prophylactic strategy were researched using a logistic regression model among the 246 treated patients. The results of univariate analysis are presented in Table 5. Multivariate analysis showed that allogeneic HSCT (OR 4.57, 95\% CI 2.47-8.47; $p<0.0001$ ), AML or MDS (OR 3.07, 95\% CI
$1.68-5.61 ; p<0.0001)$, antiviral treatment (OR $3.46,95 \%$ CI $2.11-5.67 ; p<0.0001$ ), and entry in a sterile room (OR 2.39, 95\% CI 1.51-3.79; $p<0.0002)$ were associated with systemic antifungal prophylaxis prescription.

\section{Antifungal Drugs Prescribed}

Antifungal drugs prescribed to patients who received antifungal prophylactic strategy are presented in Table 6 . Overall, 79\% of the patients who received antifungal prophylaxis during the 5-day observational period were administered an azole, $10 \%$ an intravenous amphotericin B formulation, $9 \%$ an echinocandin, and $2 \%$ a combination of two drugs. The most commonly used prophylactic drugs were fluconazole (administered to $41 \%$ of the patients who received prophylaxis), posaconazole (29\%), amphotericin B (11\%: liposomal 7\%, conventional 4\%), voriconazole $(9 \%)$, caspofungin $(7 \%)$, and micafungin $(3 \%)$. 
Table 2 Main patient's characteristics and systemic antifungal strategy according to age group

\begin{tabular}{|c|c|c|c|}
\hline & $\begin{array}{l}\text { Adults } \\
n=430\end{array}$ & $\begin{array}{l}\text { Pediatrics } \\
n=64\end{array}$ & $\begin{array}{l}\text { Total } \\
N=494\end{array}$ \\
\hline \multicolumn{4}{|l|}{ Patient's characteristics } \\
\hline \multicolumn{4}{|l|}{ Hematologic malignancy } \\
\hline Acute myeloid leukemia & $172(40)$ & $20(31)$ & $192(39)$ \\
\hline Myelodysplastic syndrome & $14(3)$ & & $14(3)$ \\
\hline Acute lymphoblastic leukemia & $64(15)$ & $32(50)$ & $96(19)$ \\
\hline Hodgkin lymphoma & $24(6)$ & $2(3)$ & $26(5)$ \\
\hline Non-Hodgkin lymphoma & $85(20)$ & $9(14)$ & $94(19)$ \\
\hline Chronic lymphoid leukemia & $12(3)$ & & $12(2)$ \\
\hline Myeloma & $41(10)$ & & $41(8)$ \\
\hline Chronic myeloid leukemia & $5(1)$ & $1(2)$ & $6(1)$ \\
\hline Other & $13(3)$ & & $13(3)$ \\
\hline Disease status (relapse or refractory) & $169(39)$ & $12(19)$ & $181(37)$ \\
\hline \multicolumn{4}{|l|}{ Underlying conditions } \\
\hline Autologous transplant & $41(10)$ & & $41(8)$ \\
\hline Allogeneic transplant ${ }^{a}$ & $135(31)$ & $12(19)$ & $147(30)$ \\
\hline Acute GVHD ${ }^{b}$ & $35(26)$ & $6(50)$ & $41(28)$ \\
\hline Neutropenia for at least 10 days & $110(26)$ & $17(26)$ & $127(26)$ \\
\hline Persistent fever refractory to antibiotic therapy & $44(10)$ & $6(9)$ & $50(10)$ \\
\hline Previous IFD & $57(13)$ & $5(8)$ & $62(13)$ \\
\hline \multicolumn{4}{|l|}{ Ongoing treatments } \\
\hline Chemotherapy & $272(63)$ & $55(86)$ & $327(66)$ \\
\hline Antibiotics & $326(76)$ & $43(67)$ & $369(75)$ \\
\hline Immunosuppressors & $136(32)$ & $25(39)$ & $161(33)$ \\
\hline Antivirals & $303(70)$ & $12(19)$ & $315(64)$ \\
\hline \multicolumn{4}{|l|}{ Time since entry in the unit } \\
\hline$\geq 30$ days & $62(14)$ & $9(14)$ & $71(14)$ \\
\hline Between 15 and 29 days & $63(15)$ & $14(22)$ & $77(16)$ \\
\hline$<15$ days & $305(71)$ & $41(64)$ & $346(70)$ \\
\hline Hospitalization in room with air treatment & $281(65)$ & $32(50)$ & $313(63)$ \\
\hline Laminar air flow room or Immunair ${ }^{\mathrm{TM}}$ bed $^{\mathrm{c}}$ & $149(53)$ & $23(72)$ & $172(55)$ \\
\hline Highly purified HEPA-filtered room ${ }^{c}$ & $79(28)$ & $9(28)$ & $88(28)$ \\
\hline Conventional room with Plasmair ${ }^{\mathrm{TM}}$ or equivalent $^{\mathrm{c}}$ & $53(19)$ & & $53(17)$ \\
\hline
\end{tabular}


Table 2 continued

\begin{tabular}{|c|c|c|c|}
\hline & $\begin{array}{l}\text { Adults } \\
n=430\end{array}$ & $\begin{array}{l}\text { Pediatrics } \\
n=64\end{array}$ & $\begin{array}{l}\text { Total } \\
N=494\end{array}$ \\
\hline \multicolumn{4}{|l|}{ Systemic antifungal strategy } \\
\hline Not treated with systemic antifungals & $204(47)$ & $44(69)$ & $248(50)$ \\
\hline Treated with systemic antifungals & $226(53)$ & $20(31)$ & $246(50)$ \\
\hline Prophylactic strategy ${ }^{\mathrm{d}}$ & $174(77)$ & $13(65)$ & $187(76)$ \\
\hline Primary $^{e}$ & $135(78)$ & $10(77)$ & $145(78)$ \\
\hline Secondary ${ }^{e}$ & $39(22)$ & $3(23)$ & $42(22)$ \\
\hline Empiric strategy ${ }^{\mathrm{d}}$ & $20(9)$ & $5(25)$ & $25(10)$ \\
\hline Preemptive or curative strategy ${ }^{\mathrm{d}}$ & $32(14)$ & $2(10)$ & $34(14)$ \\
\hline $\begin{array}{l}\text { Data are } n(\%) \text {, unless otherwise specifi } \\
G V H D \text { graft-versus-host disease, IFD in } \\
\text { a } 123 \text { patients ( } 114 \text { adults and } 9 \text { pediat } \\
\text { b Percentage of recipients receiving allo } \\
\text { c Percentage of patients hospitalized in } \\
\text { d Percentage of patients treated with sy } \\
\text { e Percentage of patients receiving a syst }\end{array}$ & $\begin{array}{l}\text { ease } \\
\text { splanted f } \\
\text { ietic stem } \\
\text { reatment } \\
\text { ls } \\
\text { prophylacti }\end{array}$ & onths & \\
\hline
\end{tabular}

Table 3 Frequency of systemic antifungal strategies according to the pathology profile

\begin{tabular}{|c|c|c|c|c|c|}
\hline & $\begin{array}{l}\text { Group } 1 \\
n=147\end{array}$ & $\begin{array}{l}\text { Group } 2 \\
n=131\end{array}$ & $\begin{array}{l}\text { Group } 3 \\
n=71\end{array}$ & $\begin{array}{l}\text { Group } 4 \\
n=145\end{array}$ & $\begin{array}{l}\text { Total } \\
n=494\end{array}$ \\
\hline Not treated with systemic antifungals & $28(19)$ & $53(40)$ & $52(73)$ & $115(79)$ & $248(50)$ \\
\hline Treated with systemic antifungals & $119(81)$ & $78(60)$ & $19(27)$ & $30(21)$ & $246(50)$ \\
\hline Prophylactic strategy $^{a}$ & $95(80)$ & $56(72)$ & $12(63)$ & $24(80)$ & $187(76)$ \\
\hline Primary ${ }^{b}$ & $75(79)$ & $48(86)$ & $10(83)$ & $12(50)$ & $145(78)$ \\
\hline Secondary ${ }^{\mathrm{b}}$ & $20(21)$ & $8(14)$ & $2(17)$ & $12(50)$ & $42(22)$ \\
\hline Empiric strategy ${ }^{\mathrm{a}}$ & $13(11)$ & $6(8)$ & $2(11)$ & $4(13)$ & $25(10)$ \\
\hline Preemptive or curative strategy ${ }^{a}$ & $11(9)$ & $16(20)$ & $5(26)$ & $2(7)$ & $34(14)$ \\
\hline
\end{tabular}

Data are $n(\%)$

a Percentage among patients treated with systemic antifungals

b Percentage among patients receiving a systemic antifungal prophylactic strategy

Slight differences were observed when comparing the patients who received primary prophylaxis $(n=145)$ to those who received secondary prophylaxis $(n=42)$ : posaconazole and fluconazole were administered to $73 \%$ of the patients receiving primary prophylaxis versus $60 \%$ of the patients receiving secondary prophylaxis, while voriconazole (either oral or intravenous) was administered to $4 \%$ of the patients receiving primary prophylaxis versus $24 \%$ of those receiving secondary prophylaxis (Table 7). 
Table 4 Characteristics of hospitalized patients receiving systemic antifungal prophylaxis according to the pathology profile

\begin{tabular}{lccccc}
\hline & $\begin{array}{l}\text { Group 1 } \\
\boldsymbol{n = 9 5}\end{array}$ & $\begin{array}{l}\text { Group 2 } \\
\boldsymbol{n}=\mathbf{5 6}\end{array}$ & $\begin{array}{l}\text { Group 3 } \\
\boldsymbol{n}=\mathbf{1 2}\end{array}$ & $\begin{array}{l}\text { Group 4 } \\
\boldsymbol{n}=\mathbf{2 4}\end{array}$ & $\begin{array}{l}\text { Total } \\
\boldsymbol{n}=\mathbf{1 8 7}\end{array}$ \\
\hline Gender (male) & $56(59)$ & $32(57)$ & $10(83)$ & $14(58)$ & $112(60)$ \\
Adults & $88(93)$ & $53(95)$ & $10(83)$ & $23(96)$ & $174(93)$ \\
Age, year, median & & & & & \\
Adult (range) & 52.2 & 54.0 & 34.9 & 55.2 & 52.7 \\
& $(21-71)$ & $(23-81)$ & $(21-67)$ & $(24-67)$ & $(21-81)$ \\
Children (range) & $7.7(0-12)$ & $\begin{array}{c}10.8 \\
(10-14)\end{array}$ & $6.9(3-11)$ & $0.5(\mathrm{NA})$ & $7.9(0-14)$
\end{tabular}

Hematologic malignancy

Acute myeloid leukemia

Myelodysplastic syndrome

Acute lymphoblastic leukemia

Hodgkin lymphoma

Non-Hodgkin lymphoma

Chronic lymphoid leukemia

Myeloma

Chronic myeloid leukemia

Other

Disease status (relapse or refractory)

Underlying conditions

Autologous transplant

Allogeneic transplant ${ }^{a}$

$\mathrm{GVHD}^{\mathrm{b}, \mathrm{c}}$

Grade I-II acute GVHD

Grade III-IV acute GVHD

Chronic GVHD

Neutropenic phase ${ }^{c}$

ANC $<0.5,10 / 1$ for at least 10 days

Persistent fever refractory to antibiotic therapy

Previous IFD

Ongoing treatments

Chemotherapy

Antibiotics
$41(43) \quad 56(100)$

$5(5)$

$16(17)$

9 (9)

$9(7)$

$1(1)$

$5(5)$

3 (3)

$6(6)$

$56(59)$

$6(11)$

$4(33)$

0

0

$15(63)$

$15(8)$

$95(100) \quad 0$

27 (28)

0

$95(51)$

$27(28)$

10

10

14

7

38 (40)

16 (17)

$28(50)$

$6(6)$

7 (13)

$19(20)$

8 (14)

$2(17)$

0

$29(16)$

$97(52)$

$5(3)$

$28(15)$

$11(6)$

$20(11)$

$1(1)$

$14(7)$

3 (2)

$10(5)$

77 (41)

14

7

$38(40)$

$54(29)$

$15(8)$

$1(4) \quad 15(8)$

$44(46) \quad 49(88)$

$12(100)$

$8(33)$

$113(60)$

$80(84) \quad 44(79)$

$11(92)$ 
Table 4 continued

\begin{tabular}{llllll}
\hline & $\begin{array}{l}\text { Group 1 } \\
\boldsymbol{n}=\mathbf{9 5}\end{array}$ & $\begin{array}{l}\text { Group 2 } \\
\boldsymbol{n}=\mathbf{5 6}\end{array}$ & $\begin{array}{l}\text { Group 3 } \\
\boldsymbol{n}=\mathbf{1 2}\end{array}$ & $\begin{array}{l}\text { Group 4 } \\
\boldsymbol{n}=\mathbf{2 4}\end{array}$ & $\begin{array}{l}\text { Total } \\
\boldsymbol{n}=\mathbf{1 8 7}\end{array}$ \\
\hline $\begin{array}{l}\text { Immunosuppressants } \\
\text { Antivirals }\end{array}$ & $87(71)$ & $3(5)$ & $6(50)$ & $2(8)$ & $78(42)$ \\
Time since entry in the unit & & $39(64)$ & $10(83)$ & $20(83)$ & $156(83)$ \\
$\geq 30$ days & $20(21)$ & $33(59)$ & $2(17)$ & $1(4)$ & $30(16)$ \\
Between 15 and 29 days & $14(15)$ & $16(29)$ & $3(25)$ & $3(13)$ & $36(19)$ \\
$<15$ days & $61(64)$ & $7(13)$ & $7(58)$ & $20(83)$ & $121(65)$ \\
Hospitalization in room with air treatment & $82(86)$ & $48(86)$ & $9(75)$ & $18(75)$ & $157(84)$ \\
Laminar air flow room or Immunair $^{\mathrm{TM}}$ bed $^{\mathrm{d}}$ & $60(73)$ & $22(46)$ & $2(22)$ & $1(6)$ & $85(54)$ \\
Highly purified HEPA-filtered room $^{\mathrm{d}}$ & $18(22)$ & $19(40)$ & $4(44)$ & $12(67)$ & $53(34)$ \\
Conventional room with Plasmair $^{\mathrm{TM}}$ or equivalent $^{\mathrm{d}}$ & $4(5)$ & $7(14)$ & $3(33)$ & $5(28)$ & $19(12)$ \\
\hline
\end{tabular}

Data are $n$ (\%), unless otherwise specified

$A N C$ absolute neutrophil count, GVHD graft-versus-host disease, IFD invasive fungal disease

${ }^{a} 82$ patients transplanted for less than 6 months

${ }^{b}$ Chronic and/or acute GVHD

${ }^{c}$ Percentage among recipients of allogeneic hematopoietic stem cell transplant

d Percentage among patients hospitalized in a room with air treatment

\section{DISCUSSION}

The AFHEM study was the first cross-sectional observational study to determine the use of antifungal treatment strategies used in hematologic patients in medical practice in France. Half of the patients hospitalized in hematology centers received a systemic antifungal agent (53\% in adults and $31 \%$ in pediatric patients), and prophylaxis was the leading strategy used.

Guidelines and expert committees suggest risk stratifying patients from very low risk to very high risk of developing IFD to determine the most appropriate antifungal strategy $[6,11,21]$. Unfortunately, there is no uniformity across the guidelines for the criteria for each group. In this study, the proportion of patients receiving systemic antifungal prophylaxis ranged from $17 \%$ to $65 \%$ of the whole population and from $63 \%$ to $80 \%$ of patients treated with antifungals, depending on the risk level for IFD. Interestingly, $81 \%$ of patients who received prophylaxis were either allogeneic
HSCT patients or AML patients, and these indications are therefore in accordance with international recommendations.

Azoles are recommended for prophylaxis in high-risk patients [5, 6, 9-11]. Guidelines from ECIL [6] and the German Society for Hematology and Medical Oncology [22] recommend that the choice of antifungal agent is based on clinical indication. For example, during the neutropenic phase following an allogeneic transplant, fluconazole is recommended for patients at low risk of developing invasive aspergillosis, but this is to be switched in patients at high risk of invasive aspergillosis (to voriconazole) or if patients develop GVHD (to posaconazole). We found that oral or intravenous fluconazole was the predominant drug used during the neutropenic phase in HSCT patients to prevent invasive candidiasis combined with sterile air conditions in to prevent IFD due to filamentous fungi, as mentioned above. Of note, if fluconazole is chosen, there is also a need for a mold-directed diagnostic 
Table 5 Factor associated with antifungal prophylactic strategy: univariate analysis

\begin{tabular}{|c|c|c|c|}
\hline & $\begin{array}{l}\text { No antifungal prophylactic strategy } \\
n=\mathbf{3 0 7}\end{array}$ & $\begin{array}{l}\text { Antifungal prophylactic strategy } \\
n=187\end{array}$ & $p$ value $^{*}$ \\
\hline \multicolumn{4}{|l|}{ Pathology profile } \\
\hline Group 1 & $52(17)$ & $95(51)$ & \multirow[t]{4}{*}{$<0.001(\mathrm{~S})$} \\
\hline Group 2 & $75(24)$ & $56(30)$ & \\
\hline Group 3 & $59(19)$ & $12(6)$ & \\
\hline Group 4 & $121(39)$ & $24(13)$ & \\
\hline \multicolumn{4}{|l|}{ Gender } \\
\hline Male & $175(57)$. & $112(60)$ & \multirow[t]{2}{*}{$0.528(\mathrm{NS})$} \\
\hline Female & $132(43)$ & $75(40)$ & \\
\hline \multicolumn{4}{|l|}{ Age group } \\
\hline Pediatrics & $51(17)$ & $13(7)$ & \multirow[t]{2}{*}{$0.002(S)$} \\
\hline Adults & $256(83)$ & $174(93)$ & \\
\hline \multicolumn{4}{|c|}{ Entry in a sterile room ${ }^{a}$} \\
\hline No & $185(60 \%)$ & $49(6 \%)$ & \multirow[t]{2}{*}{$<0.001(S)$} \\
\hline Yes & $122(40 \%)$ & $138(74 \%)$ & \\
\hline \multicolumn{4}{|l|}{ First-line treatment } \\
\hline No & $115(38)$ & $75(40)$ & \multirow[t]{2}{*}{$0.557(\mathrm{NS})$} \\
\hline Yes & $192(62)$ & $112(60)$ & \\
\hline \multicolumn{4}{|l|}{ Disease status } \\
\hline Missing values & 2 & 2 & \multirow{3}{*}{$0.094(\mathrm{NS})$} \\
\hline Initial phase & $201(66)$ & $108(58)$ & \\
\hline Relapse/refractory & $104(34)$ & $77(42)$ & \\
\hline \multicolumn{4}{|c|}{$\mathrm{ANC}<0.5,10 / 1$ for at least 10 days } \\
\hline Missing values & 1 & 0 & \multirow{3}{*}{$0.216(\mathrm{NS})$} \\
\hline No & $233(76)$ & $133(71)$ & \\
\hline Yes & $73(24)$ & $54(29)$ & \\
\hline \multicolumn{4}{|c|}{ Persistent fever refractory to antibiotherapy } \\
\hline No & $272(89)$ & $172(92)$ & \multirow[t]{2}{*}{$0.227(\mathrm{NS})$} \\
\hline Yes & $35(11)$ & $15(8)$ & \\
\hline \multicolumn{4}{|l|}{ Previous IFD } \\
\hline No & $274(89)$ & $158(85)$ & \multirow[t]{2}{*}{$0.121(\mathrm{NS})$} \\
\hline Yes & $33(11)$ & $29(15)$ & \\
\hline
\end{tabular}


Table 5 continued

$\begin{array}{lll}\begin{array}{l}\text { No antifungal prophylactic } \\ \text { strategy } n=307\end{array} & \begin{array}{l}\text { Antifungal prophylactic } \\ \text { strategy } n=\mathbf{1 8 7}\end{array} & p \text { value* }^{*}\end{array}$

Ongoing chemotherapy

$\begin{array}{lllr}\text { No } & 93(30) & 74(40) & 0.034(S) \\ \text { Yes } & 214(70) & 113(60) & \\ \text { Ongoing antibiotherapy } & & & 0.009(S) \\ \text { No } & 90(29) & 35(19) & 152(81)\end{array}$

Ongoing immunosuppressive treatment

$\begin{array}{lccc}\text { No } & 224(73) & 109(58) & 0.001(\mathrm{~S}) \\ \text { Yes } & 83(27) & 78(42) & <0.001(\mathrm{~S}) \\ \text { Ongoing antiviral treatment } & 148(48) & 31(17) & 156(83) \\ \text { No } & 159(52) & & 0.038(\mathrm{~S}) \\ \text { Yes } & 288(94) & 183(98) & 4(2) \\ \text { Ongoing monoclonal antibody } & 19(6) & \\ \text { No } & & \end{array}$

Data are $n(\%)$

$A N C$ absolute neutrophil count, IFD invasive fungal disease

*Pearson $\chi^{2}$ test (two sided)

a Sterile room is defined as Laminar flow sterile room, Immunair ${ }^{\mathrm{TM}}$ bed, or highly purified HEPA-filtered room

strategy [7]. Consistent with recommendations for patients with AML or MDS receiving intensive chemotherapy, we found that posaconazole was the main drug (63\%) used in this group of patients. The ECIL-3 guidelines also recommend voriconazole for both the neutropenic and GVHD phases in allogeneic HSCT settings. In our study, voriconazole was only rarely prescribed for prophylaxis, except in cases of secondary prophylaxis.

A French case-control study previously published in 2011 showed a significant association between prior exposure to caspofungin and an elevated risk of bloodstream infection caused by Candida spp. having reduced susceptibility to caspofungin in adults with hematologic malignancies [23]. Thus, considering these results and those published on azole resistance, use of antifungal medications always requires constant vigilance for resistance emergence, particularly during long-term prophylaxis.

Eighty-four percent of the patients receiving antifungal prophylaxis were hospitalized in rooms with air treatment, $88 \%$ of them being placed in a sterile room (in a laminar air flow room, Immunair ${ }^{\mathrm{TM}}$ bed, or highly purified HEPA-filtered room), thus combining drug administration with environmental measures to prevent systemic infections and illustrating the appropriate perception of high-risk conditions by the clinicians. The low rate of empiric, preemptive, and curative therapies in groups 1 and 2 (20\% and 28\%, respectively) might be explained by the high level and rate of prophylactic strategies. Of note, empiric therapy is used more often in children (25\%) than in adults (9\%). 
Table 6 Systemic antifungal prophylactic strategy: drugs administered according to the pathology profile

\begin{tabular}{|c|c|c|c|c|c|}
\hline & $\begin{array}{l}\text { Group } 1 \\
n=95\end{array}$ & $\begin{array}{l}\text { Group 2 } \\
n=56\end{array}$ & $\begin{array}{l}\text { Group } 3 \\
n=12\end{array}$ & $\begin{array}{l}\text { Group } 4 \\
n=24\end{array}$ & $\begin{array}{l}\text { Total } \\
n=187\end{array}$ \\
\hline Missing values & $1(1)$ & 0 & 0 & 0 & $1(0.5)$ \\
\hline Azole alone & $70(74)$ & $49(88)$ & $7(58)$ & $22(92)$ & $148(79)$ \\
\hline Amphotericin B formulation alone & $10(11)$ & $5(9)$ & $2(17)$ & $1(4)$ & $18(10)$ \\
\hline Echinocandin alone & $13(14)$ & $1(2)$ & $2(17)$ & $1(4)$ & $17(9)$ \\
\hline Amphotericin B formulation and azole & $1(1)$ & $1(2)$ & 0 & 0 & $2(1)$ \\
\hline Amphotericin B formulation and echinocandin & 0 & 0 & $1(8)$ & 0 & $1(0.5)$ \\
\hline \multicolumn{6}{|l|}{ Azole type } \\
\hline$N$ & 71 & 50 & 7 & 22 & 150 \\
\hline PO fluconazole & $38(54)$ & $5(10)$ & $4(57)$ & $16(73)$ & $63(42)$ \\
\hline IV fluconazole & $6(8)$ & $3(6)$ & 0 & $4(18)$ & $13(9)$ \\
\hline PO posaconazole & $16(23)$ & $35(70)$ & $3(43)$ & $1(5)$ & $55(37)$ \\
\hline PO voriconazole & $8(11)$ & $4(8)$ & 0 & 0 & $12(8)$ \\
\hline IV voriconazole & $3(4)$ & $1(2)$ & 0 & 0 & $4(3)$ \\
\hline Itraconazole & 0 & $1(2)$ & 0 & $1(5)$ & $2(1)$ \\
\hline Posaconazole-PO voriconazole & 0 & $1(2)$ & 0 & 0 & $1(1)$ \\
\hline \multicolumn{6}{|l|}{ Amphotericin B formulation } \\
\hline$N$ & 11 & 6 & 3 & 1 & 21 \\
\hline IV liposomal amphotericin B & $8(73)$ & $4(67)$ & $2(67)$ & 0 & $14(67)$ \\
\hline IV conventional amphotericin B & $3(27)$ & $2(33)$ & $1(33)$ & $1(100)$ & $7(33)$ \\
\hline \multicolumn{6}{|l|}{ Echinocandin type } \\
\hline$N$ & 13 & 1 & 3 & 1 & 18 \\
\hline Caspofungin & $11(85)$ & $1(100)$ & $1(33)$ & 0 & $13(72)$ \\
\hline Micafungin & $2(15)$ & 0 & $2(67)$ & $1(100)$ & $5(28)$ \\
\hline
\end{tabular}

Data are $n(\%)$

Although providing interesting information on patients receiving antifungal prophylaxis in French hematology units, our study has some limitations, mainly due to its design. First, we can assume that physician selection bias could also have led to patient selection bias. Indeed, physician participation was offered on a voluntary basis, and the final center sample may not be representative of the use of antifungal therapy in France. This potential bias is inevitable in this type of study, and its impact is difficult to evaluate. Moreover, even though the sample was comprehensive, the patients could refuse to participate in the study, and the final population may not be perfectly representative. To be included in the study, the patients (or their representative) were required to give their written approval. We established a registry to record the patients hospitalized in participating units and eligible for the study. Of the 158 patients recorded in the registry who did not give their written approval for participation in 
Table 7 Systemic antifungal drugs prescribed according to the type of prophylactic strategy

\begin{tabular}{|c|c|c|c|}
\hline & $\begin{array}{l}\text { Primary prophylaxis } \\
n=145\end{array}$ & $\begin{array}{l}\text { Secondary prophylaxis } \\
n=42\end{array}$ & $\begin{array}{l}\text { Total } \\
n=187\end{array}$ \\
\hline Missing values & $1(1)$ & 0 & $1(0.5)$ \\
\hline Amphotericin B formulation alone & $111(77)$ & $37(88)$ & $148(79)$ \\
\hline Amphotericin B alone & $15(10)$ & $3(7)$ & $18(10)$ \\
\hline Echinocandin alone & $15(10)$ & $2(5)$ & $17(9)$ \\
\hline Amphoterin B formulation and azole & $2(1)$ & 0 & $2(1)$ \\
\hline Amphotericin B formulation and echinocandin & $1(1)$ & 0 & $1(0.5)$ \\
\hline \multicolumn{4}{|l|}{ Azole type } \\
\hline$n$ & 113 & 37 & 150 \\
\hline PO fluconazole & $50(44)$ & $13(35)$ & $63(42)$ \\
\hline IV fluconazole & $12(11)$ & $1(3)$ & $13(9)$ \\
\hline PO posaconazole & $44(39)$ & $11(30)$ & $55(37)$ \\
\hline PO voriconazole & $4(4)$ & $8(22)$ & $12(8)$ \\
\hline IV voriconazole & $2(2)$ & $2(5)$ & $4(3)$ \\
\hline Itraconazole & $1(1)$ & $1(3)$ & $2(1)$ \\
\hline Posaconazole-PO voriconazole & 0 & $1(3)$ & $1(1)$ \\
\hline \multicolumn{4}{|l|}{ Amphotericin B formulation } \\
\hline$n$ & 18 & 3 & 21 \\
\hline IV liposomal amphotericin B & $11(61)$ & $3(100)$ & $14(67)$ \\
\hline IV conventional amphotericin B & $7(39)$ & 0 & $7(33)$ \\
\hline \multicolumn{4}{|l|}{ Echinocandin type } \\
\hline$n$ & 16 & 2 & 18 \\
\hline Caspofungin & $12(75)$ & $1(50)$ & $13(72)$ \\
\hline Micafungin & $4(25)$ & $1(50)$ & $5(28)$ \\
\hline
\end{tabular}

Data are $n(\%)$

the study (25\%), 128 did not receive any antifungal drug. It can thus be assumed that the proportion of patients treated with a systemic antifungal drug could have been slightly overestimated.

\section{CONCLUSION}

This work provides a comprehensive picture of patients hospitalized in French hematology units and treated with antifungal prophylaxis. Prophylaxis is now the leading strategy used in hematology, whatever the disease conditions of the patients with overall $76 \%$ of patients managed in this way. Prophylaxis is mainly based on fluconazole and posaconazole. Fluconazole is still used in allogeneic HSCT patients, in most cases associated with protected environmental conditions. Posaconazole is mainly used in AML/MDS patients, but also in ALL patients where its use is off-label. Echinocandins are 
mainly used in high-risk patients, and caspofungin is the most used echinocandin, although it is not licensed for prophylaxis. Antifungal stewardship programs are thus of prime interest to rationalize antifungal use [24]. As recently published [25], although neutropenia is common to almost all hematologic patients, other factors (low complete response probability due to an adverse karyotype in AML, high-dose dexametazone in ALL, allogeneic HSCT from donors other than a matched sibling donor) may play a key role in these patients and may help to design the most appropriate diagnostic workup and antifungal strategy.

\section{ACKNOWLEDGEMENTS}

The authors would like to thank all the patients who participated in the study. The authors would also like to thank the investigators of the AFHEM study group: Gérard Socié, Paris; Jean El Cheikh, Marseille; Stéphane Leprêtre, Rouen; Ibrahim Yakoub-Agha, Lille; Yves Perel, Bordeaux; Regis Costello, Marseille; Virginie Gandemer Delignieres and Jean-Pierre Gangneux, Rennes; Aline Schmidt, Angers; Yves Bertrand, Lyon; Patrice Ceballos, Montpellier; Gaëlle Guillerm, Brest; Anne Sirvent, Montpellier; Mauricette Michallet, Pierre-Bénite; Guy Leverger, Paris; Fabrice Larosa, Besançon; JeanPierre Vannier, Rouen; Emmanuelle Tavernier Tardy, Saint-Priest-en-Jarez.

Funding. Astellas Pharma France was the funding source for all stages of the study conduct and analysis and for all costs associated with the development and the publishing of the present manuscript. All authors had full access to all of the data in this study and take complete responsibility for the integrity of the data and accuracy of the data analysis.

Editorial Assistance. The authors thank ICTA PM for providing logistical support and performing data management and statistical analysis. Editorial assistance in the preparation of this manuscript was provided by Lise Bosquet (on behalf of ICTA PM). Support for this assistance was funded by Astellas Pharma.

Authorship. All named authors meet the International Committee of Medical Journal Editors (ICMJE) criteria for authorship for this manuscript, take responsibility for the integrity of the work as a whole, and have given final approval to the version to be published.

Disclosures. Jean-Pierre Gangneux has been a consultant to Astellas Pharma for work under consideration and has been a consultant to Astellas Pharma, Gilead, Merck, and Pfizer outside of the submitted work. Raoul Herbrecht has been a consultant to Astellas Pharma for work under consideration, has been a consultant to Astellas Pharma, Basilea, Gilead, MSD, Pfizer, and Schering-Plough outside of the submitted work, and has received a grant from Pfizer outside of the submitted work. Mauricette Michallet has been a consultant to Astellas for work under consideration. Denis Caillot has been a consultant to Astellas Pharma for work under consideration and has been a consultant to MSD outside of the submitted work. Ibrahim Yakoub-Agha has been a consultant to Astellas Pharma for work under consideration and has been a consultant to MSD outside of the submitted work. Jean El Cheikh has been a consultant to Astellas Pharma for work under consideration and outside of the submitted work. At the time of this study, Jean El Cheikh's affiliation was the Department of Transplantation and Cellular Therapy, Paoli Calmettes Institute, Marseille, France; his current affiliation is the Bone Marrow Transplant Unit, American University of Beirut Medical Center, Lebanon. Jean-Baptiste Quiniou was an employee of Astellas Pharma during the course of manuscript development; he left prior to submission. Jean-Baptiste Quiniou's current affiliation is Celgene Pharmaceuticals, Paris, France.

Compliance with Ethics Guidelines. The data were anonymized before any analysis occurred. All procedures followed were in accordance with the ethical standards of the responsible committee on human 
experimentation (institutional and national) and with the Helsinki Declaration of 1964, as revised in 2013. Informed consent was obtained from all patients for being included in the study. According to French regulatory requirements, approvals from the French review boards (Comité Consultatif sur le Traitement de l'Information en matière de Recherche dans le domaine de la Santé and Commission Nationale de l'Informatique et des Libertés) were obtained.

Data Availability. The data sets during and/ or analyzed during the current study are available from the corresponding author on reasonable request.

Open Access. This article is distributed under the terms of the Creative Commons Attribution-NonCommercial 4.0 International License (http://creativecommons.org/licenses/ by-nc/4.0/), which permits any noncommercial use, distribution, and reproduction in any medium, provided you give appropriate credit to the original author(s) and the source, provide a link to the Creative Commons license, and indicate if changes were made.

\section{REFERENCES}

1. Lass-Florl C. The changing face of epidemiology of invasive fungal disease in Europe. Mycoses. 2009;52(3):197-205.

2. Cuenca-Estrella M, Bernal-Martinez L, Buitrago MJ, et al. Update on the epidemiology and diagnosis of invasive fungal infection. Int J Antimicrob Agents. 2008;32(Suppl 2):S143-7.

3. Gangeux JP, Bougnoux ME, Hennequin C, et al. An estimation of burden of serious fungal infections in France. J Med Mycol. 2016;26(4):385-90.

4. Herbrecht R, Caillot D, Cordonnier C, et al. Indications and outcomes of antifungal therapy in French patients with haematological conditions or recipients of haematopoietic stem cell transplantation. J Antimicrob Chemother. 2012;67(11):2731-8.

5. Pappas PG, Kauffman CA, Andes D, et al. Clinical practice guidelines for the management of candidiasis: 2009 update by the Infectious Diseases
Society of America. Clin Infect Dis. 2009;48(5):503-35.

6. Maertens J, Marchetti O, Herbrecht R, et al. European guidelines for antifungal management in leukemia and hematopoietic stem cell transplant recipients: summary of the ECIL 3-2009 update. Bone Marrow Transpl. 2011;46(5):709-18.

7. Ullmann AJ, Akova M, Herbrecht R, et al. ESCMID guideline for the diagnosis and management of Candida diseases 2012: adults with haematological malignancies and after haematopoietic stem cell transplantation (HCT). Clin Microbiol Infect. 2012;18(Suppl 7):53-67.

8. Management of candidosis and aspergillosis in adults. Consensus conference organized jointly by SFAR, SPILF and SRLF with the participation of the French society of medical mycology and the French society of bone marrow transplant. Rev Pneumol Clin. 2004;60(5):289-93. http://sfar.org/wp-content/ uploads/2015/10/2_SFAR_Prise-encharge-des-candid oses-et-aspergilloses-invasives-de-l'adulte.pdf.

9. Prentice AG, Glasmacher A, Hobson RP, et al. Guidelines on the management of invasive fungal infection during therapy for haematological malignancy. $\mathrm{Br}$ Comm Stand Haematol. 2010. https://mycology.adelaide.edu.au/docs/ifi-therapy. pdf.

10. Cornely OA, Bohme A, Buchheidt D, et al. Primary prophylaxis of invasive fungal infections in patients with hematologic malignancies. Recommendations of the Infectious Diseases Working Party of the German Society for Haematology and Oncology. Haematologica. 2009;94(1):113-22.

11. Fleming S, Yannakou CK, Haeusler GM, et al. Consensus guidelines for antifungal prophylaxis in haematological malignancy and haemopoietic stem cell transplantation, 2014. Intern Med J. 2014;44(12b):1283-97.

12. Barberan J, Mensa J, Llamas JC, et al. Recommendations for the treatment of invasive fungal infection caused by filamentous fungi in the hematological patient. Rev Esp Quimioter. 2011;24(4):263-70.

13. Ullmann AJ, Lipton $\mathrm{JH}$, Vesole $\mathrm{DH}$, et al. Posaconazole or fluconazole for prophylaxis in severe graft-versus-host disease. $\mathrm{N}$ Engl J Med. 2007;356(4):335-47.

14. Thiebaut A. Prophylaxis in invasive fungal diseases: update from clinical trials. Hematologie. 2008;14:12-9.

15. Cornely OA, Aversa F, Cook P, et al. Evaluating the role of prophylaxis in the management of invasive 
fungal infections in patients with hematologic malignancy. Eur J Haematol. 2011;87(4):289-301.

16. Cordonnier C, Rovira M, Maertens J, et al. Voriconazole as secondary antifungal prophylaxis in stem cell transplant recipients. Haematologica. 2011;96(2):e9-10 (author reply e1).

17. Hicheri Y, Maury S, Pautas C, Schwarzinger M, Cordonnier C. Preemptive and empiric therapeutic strategies for invasive fungal diseases. Hematologie. 2008;14(5):20-4.

18. Cordonnier C, Pautas C, Maury S, et al. Empirical versus preemptive antifungal therapy for high-risk, febrile, neutropenic patients: a randomized, controlled trial. Clin Infect Dis. 2009;48(8):1042-51.

19. Drgona L, Colita A, Klimko N, et al. Triggers for driving treatment of at-risk patients with invasive fungal disease. $\mathrm{J}$ Antimicrob Chemother. 2013;68(Suppl 3):17-24.

20. Herbrecht R, Denning DW, Patterson TF, et al. Voriconazole versus amphotericin B for primary therapy of invasive aspergillosis. $\mathrm{N}$ Engl J Med. 2002;347(6):408-15.
21. Pagano L, Akova M, Dimopoulos G, et al. Risk assessment and prognostic factors for mould-related diseases in immunocompromised patients. J Antimicrob Chemother. 2011;66(Suppl 1):5-14.

22. Bohme A, Ruhnke M, Buchheidt D, et al. Treatment of invasive fungal infections in cancer patients-recommendations of the Infectious Diseases Working Party (AGIHO) of the German Society of Hematology and Oncology (DGHO). Ann Hematol. 2009;88(2):97-110.

23. Blanchard E, Lortholary O, Boukris-Sitbon $\mathrm{K}$, et al. Prior caspofungin exposure in patients with hematological malignancies is a risk factor for subsequent fungemia due to decreased susceptibility in Candida spp.: a case-control study in Paris, France. Antimicrob Agents Chemother. 2011;55(11):5358-61.

24. Munoz P, Valerio M, Vena A, Bouza E. Antifungal stewardship in daily practice and health economic implications. Mycoses. 2015;58(Suppl 2):14-25.

25. Pagano L, Busca A, Candoni A, et al. Risk stratification for invasive fungal infections in patients with hematological malignancies: SEIFEM recommendations. Blood Rev. 2017;31(2):17-29. 